\title{
The impact of childhood maltreatment: a review of neurobiological and genetic factors
}

\author{
Eamon McCrory ${ }^{1,2}$ *, Stephane A. De Brito ${ }^{1,2}$ and Essi Viding ${ }^{1}$ \\ ${ }^{1}$ Developmental Risk and Resilience Unit, Division of Psychology and Language Sciences, University College London, London, UK \\ 2 Research Programme, The Anna Freud Centre, London, UK
}

Edited by:

Linda Mayes, Yale University, USA

Reviewed by:

Lane Strathearn, University of

Queensland, Australia

Patrick Luyten, University of Leuven,

Belgium

\section{*Correspondence:}

Eamon McCrory, Developmental Risk and Resilience Unit, Division of

Psychology and Language Sciences, University College London, 26

Bedford Way, London WC1H OAP, UK. e-mail:e.mccrory@ucl.ac.uk
Childhood maltreatment represents a significant risk factor for psychopathology. Recent research has begun to examine both the functional and structural neurobiological correlates of adverse care-giving experiences, including maltreatment, and how these might impact on a child's psychological and emotional development. The relationship between such experiences and risk for psychopathology has been shown to vary as a function of genetic factors. In this review we begin by providing a brief overview of neuroendocrine findings, which indicate an association between maltreatment and atypical development of the hypothalamic-pituitary-adrenal axis stress response, which may predispose to psychiatric vulnerability in adulthood. We then selectively review the magnetic resonance imaging (MRI) studies that have investigated possible structural and functional brain differences in children and adults who have experienced childhood maltreatment. Differences in the corpus callosum identified by structural MRI have now been reliably reported in children who have experienced abuse, while differences in the hippocampus have been reported in adults with childhood histories of maltreatment. In addition, there is preliminary evidence from functional MRI studies of adults who have experienced childhood maltreatment of amygdala hyperactivity and atypical activation of frontal regions. These functional differences can be partly understood in the context of the information biases observed in event-related potential and behavioral studies of physically abused children. Finally we consider research that has indicated that the effect of environmental adversity may be moderated by genotype, reviewing pertinent studies pointing to gene by environment interactions. We conclude by exploring the extent to which the growing evidence base in relation to neurobiological and genetic research may be relevant to clinical practice and intervention.

\section{Keywords: child abuse, maltreatment, neuroscience, MRI, genetics, HPA, psychopathology, resilience}

\section{INTRODUCTION}

Early adversity, and in particular childhood maltreatment, has been reliably associated with an increased risk of poor outcome across a range of domains, including, physical and mental health, social and academic functioning, and economic productivity (e.g., Lansford et al., 2002; Shirtcliff et al., 2009; Currie and Widom, 2010). Over the last decade, new techniques have allowed researchers to investigate the possible impact of such adversity on both brain structure and function (e.g., Teicher et al., 2003; Caspi and Moffitt, 2006; Lupien et al., 2009). The aim of this review is to present a concise overview of those studies that have investigated the neurobiological impact of childhood maltreatment. Neuroendocrine, neuroimaging, and genetic factors are considered in turn. Space constraints mean that it is not possible to widen the focus to include many related studies of institutionalization or neglect (see instead Gunnar et al., 2006; Neigh et al., 2009). Rather, the primary focus of this review relates to the experience of childhood maltreatment, defined as an experience of physical, sexual, or emotional abuse. However, we occasionally highlight investigations of institutionalization in contexts where there remains a paucity maltreatment-related research (notably in the field of functional resonance imaging).

We first provide a short overview of the hypothalamicpituitary-adrenal (HPA) axis stress response before considering evidence that maltreatment may alter the functioning of this system in children and adults. The second and third sections review the evidence for changes at the level of regional brain structure and function, respectively. We then consider the evidence from genetic studies, including investigations of gene by environment $(\mathrm{GxE})$ interactions and epigenetic effects in humans and animals, relating these to possible mechanisms associated with vulnerability and resilience. The final sections of the review seek to consider the limitations of current research and consider the degree to which neurobiological research can help advance our clinical understanding of the impact of maltreatment.

\section{STRESS SYSTEMS AND EARLY ADVERSITY MALTREATMENT AND THE HPA SYSTEM}

The HPA axis represents one of the body's core stress response systems. Exposure to stress triggers release of corticotrophin releasing hormone (CRH) and arginine vasopressin (AVP) release from the 
paraventricular nucleus of the hypothalamus, which in turn stimulate secretion of adrenocortico-trophic hormone (ACTH) that acts on the adrenal cortex to synthesize cortisol. Feedback loops at several levels ensure that the system is returned to homeostasis since chronically elevated cortisol levels can have deleterious effects on health (Lupien et al., 1998).

\section{CHILDREN WHO HAVE EXPERIENCED MALTREATMENT}

Findings from studies investigating HPA axis activity in children and adolescents with a history of maltreatment are mixed (Tarullo and Gunnar, 2006). For example, in one study of HPA axis response to CRH stimulus (Kaufman et al., 1997) reported ACTH hyper-responsiveness, but only among a subsample of maltreated children who were depressed and still exposed to a stressful home environment; no differences were found in cortisol measures. By contrast, Hart et al. (1995) in a study of preschoolers who had experienced maltreatment reported a pattern of cortisol suppression in situations of stress that was associated with social competence.

Most studies have collected basal cortisol level data given the ethical and practical implications of pharmacological challenge tests with children. Several studies have reported elevated basal cortisol levels (De Bellis et al., 1999a; Cicchetti and Rogosch, 2001; Carrion et al., 2002) while others have reported cortical suppression (Hart et al., 1995). One explanation for these apparently contradictory findings is that elevation is associated with the presence of a concurrent affective disorder (Tarullo and Gunnar, 2006). For example, two studies have reported a rise in cortisol levels across the day for maltreated children with depression, but no effects in maltreated children without depression (Kaufman, 1991; Hart et al., 1996). This pattern is also consistent with the elevated ACTH response to $\mathrm{CRH}$ in the maltreated-depressed group noted above (Kaufman et al., 1997). Other studies have reported similar elevations in relation to maltreated children with post-traumatic stress disorder (PTSD; Carrion et al., 2002) and dysthymic girls who had been sexually abused (De Bellis et al., 1994). While this pattern of elevated cortisol also characterizes non-maltreated children with affective disorders (e.g., Goodyer et al., 1998) it is not clear if maltreatment contributes an additional effect (Cicchetti and Rogosch, 2001; Cicchetti et al., 2001). It should also be noted that several studies of children with antisocial behavior have reported reduced basal cortisol concentrations and lower cortisol levels when exposed to stress (see van Goozen and Fairchild, 2008 , for a comprehensive review). It is possible that that exposure to early adversity in these children leads to a pattern of stress habituation over time, a pattern that increases the risk of difficulties in emotional and behavioral regulation; equally, reduced stress responsivity may emerge as a result of genetic factors, or GxE interactions (van Goozen and Fairchild, 2008).

\section{ADULTS WHO HAVE EXPERIENCED MALTREATMENT AS CHILDREN}

Heim and colleagues propose that childhood maltreatment increases the risk of developing depression due to a sensitization of the neurobiological systems implicated in stress adaptation and response (Heim et al., 2008). In an early study using the standardized Treir Social Stress Test (requiring public speaking and mental arithmetic) they reported that women with a history of maltreatment with and without depression exhibited an increased ACTH response compared with controls (Heim et al., 2002). A history of childhood abuse was found to be the strongest predictor of ACTH responsiveness; this was amplified by the experience of further trauma in adulthood (Heim et al., 2002). More recently, Heim et al. (2008) used the combined pharmacological test of HPA functioning (the dexamethasone/CRF challenge) with a sample of men with and without childhood maltreatment and current depression. A pattern of increased cortisol response was reported in the context of a failure of the glucocorticoid-mediated negative feedback loop to adequately control HPA activation (Heim et al., 2008). These studies suggest that major depression subsequent to childhood maltreatment is associated with inadequate inhibitory feedback regulation of the HPA axis. We know from animal models that low levels of maternal care are associated with reduced concentration of glucocorticoid receptors in the hippocampus (Liu et al., 1997); it is thus possible that a similar mechanism may account, at least in part, for the observed changes in HPA regulation in humans following maltreatment.

A parallel set of research studies has investigated PTSD in a wide range of populations including those with a prior history of maltreatment. Findings from this literature have been mixed at best (Shea et al., 2004); however a recent systematic review and metaanalysis supports the view that PTSD is associated with a general pattern of hypocortisolism, with reduced cortisol levels, at least in the afternoon (Meewisse et al., 2007). Furthermore, Meewisse et al. (2007) highlight the relationship between lower cortisol levels and PTSD in the context of physical and sexual forms of abuse. These findings therefore indicate a possible distinct patterns of adaptation across the two disorders, with HPA hypoactivity characterizing those with maltreatment-related PTSD (Meewisse et al., 2007) and hyperactivity of the HPA system characterizing maltreated individuals presenting with depression (e.g., Heim et al., 2002). These differing patterns may in part reflect adaptations of the HPA axis to different forms of maltreatment, different periods of onset and chronicity, and differential genetic susceptibility. Equally, methodological confounds may account for some of the reported differences, including the frequently observed comorbidity of depression and PTSD (Newport et al., 2004).

\section{SUMMARY: STRESS SYSTEMS AND EARLY ADVERSITY}

Early trauma, including physical, sexual, and emotional abuse is associated with increased risk of psychopathology in childhood and adulthood, as well as social and health problems (Gilbert et al., 2009). There is persuasive evidence from human (and animal) studies of a link between early stress and atypical HPA functioning. Specifically, it appears that childhood maltreatment may lead to atypical responsiveness of the HPA axis to stress, which in turn predisposes to psychiatric vulnerability in later life (van Goozen and Fairchild, 2008). While there is general agreement around this broad principle, the putative mechanisms of how dysregulation of the HPA axis might mediate the link between stress and psychopathology and the precise nature of any interaction remain less clear (see Miller et al., 2007). It is possible that diminished cortisol responsiveness (for example) may emerge if early chronic stress leads to an initial hyper-activation of the HPA system which then progresses over time to a state of hyporeactivity, as a form 
of adaptation following sustained exposure to ACTH (e.g., Fries et al., 2005).

\section{STRUCTURAL BRAIN DIFFERENCES ASSOCIATED WITH MALTREATMENT}

A growing body of research has investigated how stress, and specifically different forms of childhood maltreatment, can influence neural structure and function. These studies have employed both children who have experienced maltreatment and adults reporting childhood histories of early adversity. In the following section we first consider those studies that have investigated differences in brain structure, before considering the evidence from the smaller number of studies that have investigated the impact on brain function.

\section{HIPPOCAMPUS}

\section{Children who have experienced maltreatment}

A substantial body of animal research has shown that the hippocampus plays a central role in learning and various aspects of memory (Mizomuri et al., 2007) and that memory function is impaired in animals that have been exposed to chronic stress (McEwen, 1999). De Bellis et al. (1999b) were the first to report that maltreated children with PTSD presented with smaller intracranial and cerebral volumes, smaller corpus callosum (CC) and larger lateral ventricular volume compared to healthy, non-maltreated children. It was notable that the expected decrease in hippocampal volume, based on previous studies of adults with PTSD was not observed. Since that time, over 10 structural MRI (sMRI) studies of children and adolescents with PTSD following maltreatment have consistently failed to detect the adult pattern of lower hippocampal volume (e.g., Carrion et al., 2001; Woon and Hedges, 2008; Jackowski et al., 2009; Mehta et al., 2009).

\section{Adults who have experienced maltreatment as children}

By contrast, with the exception of one study (Pederson et al., 2004), reduced volume of the hippocampus has generally been reported for adults who have experienced maltreatment as children (Vythilingam et al., 2002; Vermetten et al., 2006; Woon and Hedges, 2008). Two explanations have been proposed to account for the discrepancy of child and adult findings (see Lupien et al., 2009). The neurotoxicity hypothesis, based on data from both animal and human studies, postulates that stress-induced prolonged exposure to glucocorticoids can lead to a reduction in hippocampal cell complexity and even lead to cell death (e.g., Sapolsky et al., 1990). Thus, it is possible that in humans, hippocampal volume reduction may result from years or decades of PTSD or chronic stress. In support of this hypothesis, (Carrion et al., 2007) in a longitudinal study reported that cortisol levels and PTSD symptoms at baseline predicted the degree of hippocampal volume reduction over an ensuing 12- to 18-month interval in 15 maltreated children with PTSD. Alternatively, the vulnerability hypothesis posits that a smaller hippocampal volume in individuals with PTSD is not a consequence of stress, but rather a predisposing risk factor for the disorder present in some individuals prior to any traumatic experience (e.g., Gilbertson et al., 2002). Further longitudinal studies and studies taking advantage of identical twins discordant for maltreatment exposure are required to distinguish between these competing accounts.

\section{AMYGDALA}

Children who have experienced maltreatment

The amygdala plays a key role in evaluating potentially threatening information, fear conditioning, emotional processing, and memory for emotional events (Phelps and LeDoux, 2005). In animal studies chronic stress has been shown to increase dendritic arborization in the amygdala (e.g., Vyas et al., 2003). It would therefore seem reasonable to predict that differences in amygdala structure would be associated with childhood maltreatment (Lupien et al., 2009). Until recently there was a consensus that children with maltreatment-related PTSD did not differ in terms of amygdala volume compared to non-maltreated children (Woon and Hedges, 2008). However, two recent studies have reported increased amygdala volumes in children and adolescents who had experienced early institutionalization and subsequent adoption. Mehta et al. (2009) reported greater amygdala volume in 14 adoptee adolescents who had experienced severe early institutional deprivation in Romania compared to a group of nondeprived, non-adopted UK controls. Similarly (Tottenham et al., 2010) reported greater amygdala volume in 17 mainly preadolescent children who had been adopted out of an orphanage when older that 15 months compared to non-adopted controls or early adopted children. A significant correlation is also reported between amygdala volume and age of adoption, suggesting that early and extended exposure to institutionalized care may lead to atypical development of limbic circuitry. It is noteworthy that the effects of early adversity on the amygdala in these two studies were observed even many years after the adversity had ceased, which is in line with evidence from animal research (Lupien et al., 2009).

\section{Adults who have experienced maltreatment as children}

To date only three studies have examined amygdala volume in adults with a history of childhood maltreatment; one found reduced volume in female patients with dissociative identity disorder as compared to healthy females (Vermetten et al., 2006) while the other two reported no measurable differences (Bremner et al., 1997; Andersen et al., 2008). While it is too early to draw definitive conclusions regarding impact of maltreatment on amygdala development, these preliminary findings suggest that the amygdala is vulnerable to early and severe stress in the context of parental loss and institutionalization. However, it appears that less severe, timelimited, and developmentally later exposure has a weaker impact on amygdala volume.

\section{CORPUS CALLOSUM AND OTHER WHITE MATTER TRACTS Children who have experienced maltreatment}

The CC is the largest white matter structure in the brain and controls inter-hemispheric communication of a host of processes, including, but not limited to, arousal, emotion, and higher cognitive abilities (Kitterle, 1995; Giedd et al., 1996). Crucially, in terms of development, nerve fiber connections passing though this region are fully formed before birth with myelination continuing throughout childhood and adulthood (Giedd et al., 1996; Teicher et al., 2004). Teicher et al. (2004) have speculated that different regions of the CC might have different windows of vulnerability to early experience. With the exception of one study (Mehta et al., 2009), decreases in CC volume (particularly middle and posterior 
regions) have consistently been reported in maltreated children and adolescents compared to non-maltreated peers (De Bellis et al., 1999b, 2002; De Bellis and Keshavan, 2003; Teicher et al., 2004; Jackowski et al., 2008). Furthermore, preliminary evidence suggests that these effects are characterized by sex-dependent differences (De Bellis and Keshavan, 2003; Teicher et al., 2004). It may be speculated that these structural abnormalities within the CC may be associated with some of the emotional and cognitive impairments that have been reported in maltreated individuals (e.g., Pears et al., 2008).

A recent study that employed diffusion tensor imaging (DTI) found decreased fractional anisotropy values (indicative of decreased white matter fiber tracts coherence or lower density of white matter fiber tracts) in maltreated children in frontal and temporal white matter regions, as compared to non-maltreated children (Govindan et al., 2010). Similar to an earlier DTI study in maltreated children (Eluvathingal et al., 2006), group differences were also observed in the uncinate fasciculus, which connects the orbitofrontal cortex (OFC) to the anterior temporal lobe, including the amygdala (Govindan et al., 2010). Interestingly, the reduction in fractional anisotropy observed by Govindan and colleagues was associated with longer periods within an orphanage and may partly underpin some of the cognitive and socioemotional impairments associated with early severe deprivation.

\section{Adults who have experienced maltreatment as children}

A study of adult females with maltreatment-related PTSD has also reported smaller area of the posterior midbody of the CC as compared to healthy controls (Kitayama et al., 2007). More recently, a recent DTI study in a non-clinical sample examined the effects of severe parental verbal abuse (e.g., ridicule, humiliation, and disdain) on brain connectivity; three white matter tracts were reported to show reduced fractional anisotropy (Choi et al., 2009). Again, the researchers hypothesized that these abnormalities may underlie some of the language and emotional regulation difficulties seen in victims of childhood maltreatment.

\section{PREFRONTAL CORTEX}

\section{Children who have experienced maltreatment}

The prefrontal cortex (PFC) is extensively interconnected with other cortical and subcortical regions consistent with its major role in the control of many aspects of behavior, cognition, and emotion regulation (Fuster, 1997; Davidson et al., 2000; Miller and Cohen, 2001). There are mixed findings from studies comparing PFC volume of children with maltreatment-related PTSD and non-maltreated children. One study reported no group difference (De Bellis et al., 1999b), but another found smaller prefrontal volume and prefrontal white matter (De Bellis et al., 2002) in the maltreated group, while the two most recent studies - one using voxel-based morphometry (VBM; provides a measure of regional volume differences by analyzing spatially normalized brain segments on a voxel-wise basis) investigating PTSD - observed larger gray matter volume of the middle-inferior and ventral regions of the PFC in the clinical groups (Richert et al., 2006; Carrion et al., 2009).

Tensor-based morphometry (TBM) provides a measure of regional volume by examining regional shape differences via analyses of the deformation fields. A recent study used TBM to compare 31 children with documented histories of physical abuse without PTSD to 41 non-abused children matched for age, pubertal stage, and gender (Hanson et al., 2010). One of the largest reported differences was observed in the right OFC. The abused group were found to have significantly smaller brain volumes in this region, differences which in turn correlated with poorer social functioning. Given that the OFC is known to play a key role in emotion and social regulation, the authors suggest that these alterations in OFC structure may partly represent the biological mechanism linking early social learning to later behavioral outcomes. However, we know that cortical thickness of the OFC is susceptible to thinning following prenatal exposure to maternal cigaret smoking and to drug taking, risk factors likely to characterize a proportion of those in a maltreated sample (Lotfipour et al., 2009). Further research will be necessary to tease apart possible risk factors that may influence structural development of this region.

A lack of consistency regarding observed structural differences in the PFC may relate to methodological differences, sample differences in age range of participants, variation in maltreatment type and chronicity, and a focus on different regions within the PFC. In addition, while it is likely that there are specific windows of vulnerability in brain development, we know little about how maltreatment at different points in development impacts different brain regions. In a unique cross-sectional study, Andersen et al. (2008) found that gray matter volume of the frontal cortex was maximally affected by abuse at ages $14-16$ years, while the hippocampus and CC were maximally affected at ages $3-5$ and 9-10 years respectively, indicating that the frontal cortex in this sample was particularly susceptible to structural change following abuse during the adolescent period. Further work exploring how regional brain differences may emerge depending on the timing of maltreatment is essential if we are to formulate a developmentally informed picture of the impact of such adversity on neurobiological development.

\section{Adults who have experienced maltreatment as children}

In contrast to the studies on maltreated children, decreased PFC volume in adults with a history of childhood maltreatment has been a consistent finding. For example, in a non-clinical sample, Tomoda et al. (2009) found that harsh childhood corporal punishment was associated with reduced gray matter volume in the left dorsolateral PFC and the right medial PFC, two brain regions central to higher cognitive processing, such as working memory and to aspects of social cognition, respectively (Miller and Cohen, 2001; Amodio and Frith, 2006). In another study, in comparison to healthy individuals, patients with major depressive disorder who reported a history of childhood maltreatment exhibited reduced volume of the rostral anterior cingulate cortex (ACC), which was negatively correlated with both cortisol levels and maltreatment severity (Treadway et al., 2009). Despite important limitations (such as the lack of information on the age of onset and duration of maltreatment) this study suggests that the rostral ACC, like the hippocampus, might be vulnerable to prolonged glucocorticoid exposure resulting from chronic stress, which in turn may decrease its ability to exert negative feedback control over HPA regulation (Treadway et al., 2009). Finally, a recent study compared healthy 
controls and patients with depression and/or anxiety disorders reporting childhood emotional maltreatment before age 16 to a group composed of healthy controls and patients who reported no childhood abuse (van Harmelen et al., 2010). The authors reported that emotional abuse was associated with a reduction in left dorsal medial PFC, even in the absence of physical or sexual abuse in childhood. Crucially, this group difference was independent of gender and could not be attributed to current psychopathology, which support the idea that the observed brain differences might be associated with the experience of maltreatment.

\section{SUMMARY: STRUCTURAL BRAIN DIFFERENCES ASSOCIATED WITH MALTREATMENT}

The findings from the structural studies reviewed above are summarized in Table 1. It is clear that there is relatively consistent evidence for reduced CC volume in children and adults who have experienced adversity, some evidence of greater amygdala volume in late-adopted previously institutionalized children, and a relatively clear pattern of normal hippocampal volume during childhood, which contrasts with the consistent finding of reduced hippocampal volume seen in adults with histories of abuse. It has recently been suggested that variations in developmental timing and age of measurement may partly account for the observed variability in the findings for structural differences in the amygdala and hippocampus (Tottenham and Sheridan, 2010). The structural findings are more mixed for the PFC in maltreated children, but there is a consistent pattern of decreased PFC volume among adults with childhood histories of maltreatment. However, a recent finding highlights that structural differences in the OFC may be linked to degree of social difficulty in physically abused children even in the absence of PTSD (Hanson et al., 2010).

\section{FUNCTIONAL BRAIN DIFFERENCES ASSOCIATED WITH MALTREATMENT CHILDREN WHO HAVE EXPERIENCED MALTREATMENT}

In contrast to the research examining structural brain differences associated with maltreatment, there are as yet relatively few that have used functional MRI (fMRI). To date, only five fMRI studies have investigated children exposed to early adversity, and only two from the same research group have recruited children who have experienced maltreatment. These studies by Carrion and colleagues investigated cognitively oriented processes. The first, which compared youths with post-traumatic stress symptoms (PTSS) secondary to maltreatment (i.e., trauma related to physical and sexual abuse and exposure to violence) with healthy controls, investigated response inhibition (Carrion et al., 2008). Increased activation in the ACC was reported in maltreated participants as compared to controls. This result is consistent with a model in which impaired cognitive control arises in the context of heightened subcortical reactivity to negative affect, potentially conferring an increased risk for psychopathology (Mueller et al., 2010). The second study used a verbal declarative memory task and compared youths with PTSS secondary to maltreatment with healthy controls (Carrion et al., 2010). During the retrieval component of the task, the youths with PTSS exhibited reduced right hippocampal activity, which was associated with greater severity of avoidance and numbing symptoms.
Three other fMRI studies have investigated the impact of early institutionalization. Using an emotional face processing paradigm, children exposed to such adversity were found to exhibit increased amygdala response to threatening facial cues (Maheu et al., 2010; Tottenham et al., 2011). It is not yet clear if these findings of atypical emotional processing generalize to children who have experienced maltreatment, such as physical, sexual, and emotional abuse. Another study assessed response inhibition and observed increased activation in the ACC in previously institutionalized children as compared to controls (Mueller et al., 2010).

While the main strength of fMRI is its good spatial resolution in relation to brain activity, event-related potentials (ERP) record the brain's electrical activity and yield detailed information about the temporal sequence (resolution in milliseconds) of cognitive operations throughout the brain (i.e., mental chronometry). Much of the existing ERP research has compared the pattern of brain response of maltreated children and healthy children when processing facial expressions, an ability that is usually mastered by the preschool years (Izard and Harris, 1995). When compared with never institutionalized children, institutionalized children who have experienced severe social deprivation show a pattern of cortical hypoactivation when viewing emotional facial expressions (Parker and Nelson, 2005), and familiar and unfamiliar faces (Parker et al., 2005). A second set of important studies by Pollak and colleagues has demonstrated that school-aged children who had been exposed to physical abuse allocate more attention to angry faces (Pollak et al., 1997, 2001) and require more attentional resources to disengage from such stimuli (Pollak and Tolley-Schell, 2003) leading to problems with emotional regulation that may predispose to anxiety (Shackman et al., 2007). Findings consistent with this pattern have also been obtained with toddlers who experienced maltreatment in their first year of life (Cicchetti and Curtis, 2005). It appears therefore that some maltreated children allocate more resources and remain hyper-vigilant to social threat cues in their environment, potentially at the cost of other developmental processes.

\section{ADULTS WHO HAVE EXPERIENCED MALTREATMENT AS CHILDREN}

Three fMRI studies using a range of paradigms have compared adults with a history of childhood maltreatment to adults without such a history. Using a flanker task with face stimuli, Grant et al. (2011) observed a robust positive correlation between physical abuse and right amygdala response to sad faces in sample including 20 patients with depression and 16 healthy controls. Importantly, group differences indicated that heightened amygdala response to sad faces was not a characteristic of individuals with depression, but rather of those with a significant history of maltreatment. This pattern of amygdala response to negative faces is consistent with that observed in maltreated children in the studies reviewed above. Dillon et al. (2009) recently investigated reward processing using a monetary incentive delay task and found that adults with a history of childhood maltreatment, relative to peers with no history of adversity, reported higher depressive symptoms, rated reward-predicting cues as less positive, and exhibited a blunted brain response to reward cues in the left pallidus. According to the authors, this result suggests a possible link between childhood adversity and later depressive psychopathology. Given the overlap 
Table 1 | Structural magnetic resonance brain imaging studies comparing maltreated to non-maltreated individuals.

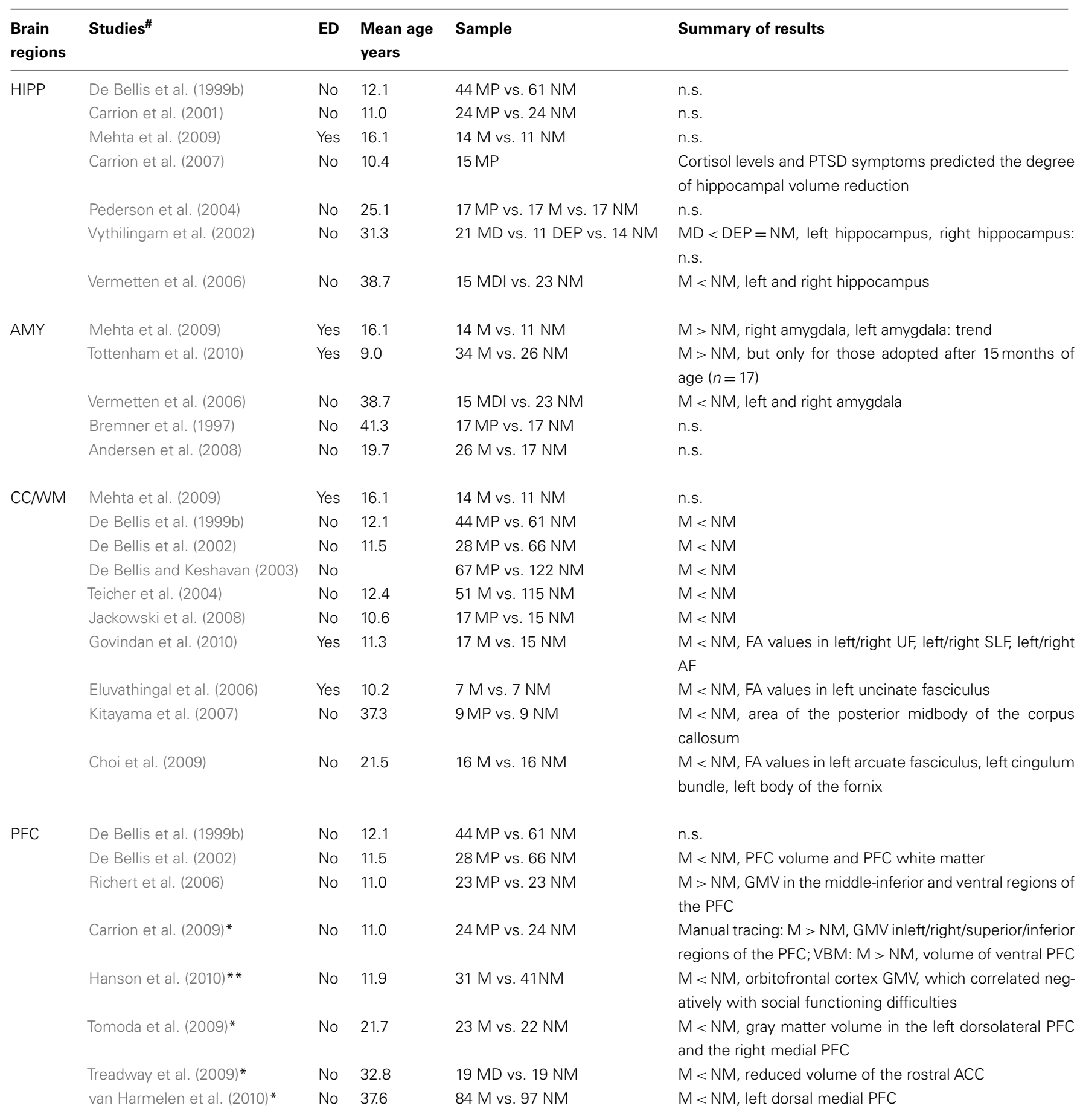

ACC, anterior cingulate cortex; $A F$, arcuate fasciculus; $A M Y, A m y g d a l a ; C C$, corpus callosum; DEP, depression; ED, early deprivation; GMV, gray matter volume; HIPP, hippocampus; $M$, maltreated; $M D$, maltreated with depression; MDI, maltreated with dissociation; MP, maltreated with PTSD/PTSD symptomatology; NM, nonmaltreated; n.s., not statistically significant; PFC, prefrontal cortex; PTSD, post-traumatic stress disorder; SLF, superior longitudinal fasciculus; UF, uncinate fasciculus; VBM, voxel-based morphometry; WM, white matter.

"All the studies used manual tracing to define their region of interest except: * Voxel-based morphometry; * Tensor-based morphometry. 
between the brain regions previously identified in sMRI studies in maltreated populations and the projection area of the olfactory system, such as the amygdala, OFC, and hippocampus, Croy et al. (2010) compared neural response to neutral and pleasant olfactory stimulation between female patients from a psychosomatic clinic with $(n=12)$ and without $(n=10)$ a history of childhood abuse. Results indicated that, despite similar group ratings for hedonic and intensity values of the stimuli and normal neural activation in olfactory projection areas, patients with a history of childhood maltreatment displayed increased activation in the posterior cingulate cortex and decreased activation in the subgenual ACC, possibly indicative of altered processing of non-traumatic stimuli.

\section{SUMMARY: FUNCTIONAL BRAIN DIFFERENCES ASSOCIATED WITH MALTREATMENT}

Studies of adults using fMRI suggest that the experience of maltreatment may be associated with hyperactivity of the amygdala in response to negative facial affect; such an effect has also been reported in children who have experienced early institutionalization. Studies of maltreated children that have examined response inhibition have observed increased activity in the ACC. The findings from these fMRI studies of children and adults are summarized in Table 2. ERP studies have found increased responses to angry faces in prefrontal regions consistent with increased attentional monitoring for social threat.

\section{THE GENETICS OF RESILIENCE AND VULNERABILITY DO GENETIC DIFFERENCES ACCOUNT FOR INDIVIDUAL DIFFERENCES IN RESILIENCE AND VULNERABILITY?}

Many recent studies have measured the biological impact of environmental adversity by taking into account genetic differences that may constrain the stress response and increase the likelihood of resilience vs. vulnerability following maltreatment (Moffitt et al., 2005). Twin and adoption studies have demonstrated that many of the psychiatric outcomes that are associated with maltreatment, such as PTSD, depression, and antisocial behavior, are partly heritable (e.g., Sullivan et al., 2000; Rhee and Waldman, 2002; Koenen et al., 2008). In other words, individual differences in susceptibility to these disorders are partly driven by genetic influences. Despite demonstrable heritable influences, it is not the case that there are genes for PTSD, depression, or antisocial behavior. Rather, there are genetic variants each adding a small increment to the probability that someone may develop or be protected from developing a psychiatric disorder (Plomin et al., 1994). It is believed that these genetic variants act across the lifespan by biasing the functioning of several brain and hormonal circuits, which mediate the body's response to stress (Viding et al., 2006).

For example, linkage and association studies have implicated variants within several genes, such as monoamine oxidaseA (MAOA), Brain-Derived Neurotrophic Factor (BDNF), serotonin transporter (5-HTT), and catechol-O-methyl transferase (COMT) in the etiology of PTSD, depression, and antisocial behavior (e.g., Craig, 2007; Feder et al., 2009). Several issues should be borne in mind when considering these genetic findings. Firstly, for every study reporting a positive association between a gene and a disorder there seem to be an equal or larger number of negative findings. This is not surprising. Given the assumed small main effect of any single gene on behavioral outcome, the reliable detection of a main effect will require a degree of statistical power that is beyond most existing studies. Secondly, although the genes influencing stress reactivity are likely to act in an additive manner, gene-gene interactions have also been reported to drive individual differences in stress reactivity; for example, carrying two risk-associated gene variants may confer a greater level of vulnerability to stress reactivity compared to the combined risk conferred by each separately (e.g., Kaufman et al., 2006). Thirdly, several GxE interaction studies have demonstrated that in addition to conferring vulnerability to environmental adversity, genetic make-up can

Table 2 | Functional magnetic resonance brain imaging studies comparing maltreated to non-maltreated individuals.

\begin{tabular}{|c|c|c|c|c|c|}
\hline Studies & ED & Mean age years & Sample & Task & Summary of results \\
\hline Maheu et al. (2010) & Yes & 13.6 & $11 \mathrm{M}$ vs. $19 \mathrm{NM}$ & $\mathrm{FP}$ & $\begin{array}{l}M>N M \text {, left amygdala in response to fearful and angry faces, } \\
\text { right amygdala: n.s. }\end{array}$ \\
\hline Tottenham et al. (2011) & Yes & 10.1 & $22 \mathrm{M}$ vs.22 NM & $\mathrm{FP}$ & $\mathrm{M}>\mathrm{NM}$, in left and right amygdala in response to fearful faces \\
\hline Carrion et al. (2008) & No & 13.5 & $16 \mathrm{MP}$ vs.16 NM & GNG & $\begin{array}{l}M>N M \text {, in left and right } A C C \text { when in contrast no-go minus go } \\
\text { trials }\end{array}$ \\
\hline Mueller et al. (2010) & Yes & 13.0 & $12 \mathrm{M}$ vs. $21 \mathrm{NM}$ & STOP & $\begin{array}{l}M>N M \text {, in left and right } A C C \text { when contrast correct change } \\
\text { minus correct go }\end{array}$ \\
\hline Carrion et al. (2010) & No & 13.9 & 16 MP vs. 11 NM & VDM & $\begin{array}{l}M<N M \text {, right HIPP activity negatively correlated with symptoms } \\
\text { severity, left HIPP: n.s. }\end{array}$ \\
\hline Grant et al. (2011) & No & 32.8 & $\begin{array}{l}10 \mathrm{MD} \text { vs. } 10 \mathrm{M} \\
\text { vs. } 16 \mathrm{NM}\end{array}$ & FTF & $\begin{array}{l}M>M D=N M \text {, in right amygdala response to sad faces, left } \\
\text { amygdala: n.s. }\end{array}$ \\
\hline Dillon et al. (2009) & No & 30.8 & $13 \mathrm{M}$ vs. $21 \mathrm{NM}$ & $R / L-P$ & $\begin{array}{l}\mathrm{M}<\mathrm{NM} \text {, blunted brain response to reward cues in the left } \\
\text { pallidus }\end{array}$ \\
\hline Croy et al. (2010) & No & 39.9 & $12 \mathrm{M}$ vs. $10 \mathrm{NM}$ & OS & $\begin{array}{l}M>N M \text {, increased activation in posterior cingulate cortex and } \\
\text { decreased activation in subgenual } A C C\end{array}$ \\
\hline
\end{tabular}

ACC, anterior cingulate cortex; ED, early deprivation; FP, face processing; FTF, Flanker task with face stimuli; GNG = Go/No-go; $M$, maltreated; MD, maltreated with depression; MP, maltreated with PTSD/PTSD symptomatology; NM, non-maltreated; R/L-P, reward/loss processing; STOP, stop task; VDM, verbal declarative memory. 
also denote resilience. Finally, the vulnerability effects exerted by the genes do not appear to be disorder specific. In other words, the same risk genes are often implicated in the etiology of several disorders associated with maltreatment/adversity. For example, 5-HTT has been associated with PTSD, depression, and antisocial behavior (e.g., Cicchetti et al., 2007; Feder et al., 2009).

\section{THE INTERACTION OF GENES AND ENVIRONMENT IN CONFERRING RISK OR RESILIENCE}

There is intuitive appeal of a biologically driven predisposition (genes) interacting with environmental factors to produce an individual's phenotype (i.e., the classic notion put forward by the stress-diathesis model). GxE research has taken off in recent years following the first seminal reports of gene-environment interaction by Caspi et al. (2002). Much of this work has focused on outcomes of early stress and maltreatment as a function of genotype. Caspi et al. (2002) were the first to report on an interaction of a measured genotype (MAOA) and environment (maltreatment) for a psychiatric outcome and demonstrated that individuals who are carriers of the low activity allele (MAOA-1), but not of the high activity allele (MAOA-H), are at an increased risk for antisocial behavior disorders following maltreatment.

This finding has since been replicated by several other research groups (see Taylor and Kim-Cohen, 2007; Weder et al., 2009) and imaging genetic studies have found that the risk, MAOA1 , genotype is related to hyper-responsivity of the brain's threat detection system and reduced activation in emotion regulation circuits, as well as to structural differences (in males) in key regulatory regions, such as OFC (Meyer-Lindenberg et al., 2006). This work suggests that a mechanism by which MAOA genotype engenders vulnerability to (reactive) aggression following maltreatment may include increased and poorly regulated neural reactivity to threat cues in the environment (Viding and Frith, 2006).

These studies suggest that genotypes potentially serve as predictors of both risk and resilience for adult psychiatric outcomes for people who have survived childhood maltreatment and abuse. GxE research has also suggested that positive environmental influences, such as social support, can buffer genetic and environmental risk for psychopathology and promote resiliency. Kaufman et al. (2006) demonstrated that children with genetic vulnerability (BDNF met allele and two 5-HTT short alleles) and environmental risk (maltreatment) were less likely to develop depression if they had social support. This finding illustrates the importance of considering positive environmental influences (such as contact with a supportive attachment figure) and how these may be protective even in the context of genetic vulnerability.

\section{EPIGENETICS AND THE IMPACT OF EARLY REARING ENVIRONMENT}

The risk effects of a gene may never manifest if that gene is not actually expressed. The regulation of gene expression has been proposed as a potential molecular mechanism that can mediate maladaptations (vulnerability) as well as adaptations (resilience) in the brain (Tsankova et al., 2007). These "epigenetic" mechanisms refer to complex processes by which environmental influences can serve to regulate gene activity without altering the underlying DNA sequence. We now know that epigenetic regulation is a candidate mechanism through which care-giving behaviors, at least in animals, may produce long-lasting effects on HPA activity and neuronal function (e.g., Weaver et al., 2004). In other words, epigenetic modification of gene expression may help explain the link between a set of maternal behaviors (high licking and grooming of rat pups early in life) and more modest HPA responses to stress (Weaver et al., 2004). One striking finding from this work is that cross-fostering can reverse the epigenetic methylation changes associated with less attentive maternal care highlighting the ongoing importance of environmental influences (both positive and negative) in shaping the stress response at the biological level. Such reversibility has important implications for intervention.

A recent animal study investigating epigenetic effects of maltreatment employed a rodent model in which infant rats were exposed to stressed caretakers that showed abusive behaviors (Roth et al., 2009). It was reported that early maltreatment produced persisting changes in methylation of BDNF DNA. Critically, the methylation changes altered BDNF gene expression in the adult PFC and hippocampus. This finding is of particular interest as it documents "epigenetic" effects of maltreatment in brain areas that are known to be both structurally and functionally altered in adults following maltreatment. Roth et al. (2009) also observed altered BDNF DNA methylation in the offspring of these females that had previously been exposed to maltreatment as pups. This suggests the possibility of a trans-generational transmission of changes in gene expression and behavior associated with early maltreatment, even in a new generation of animals who had not been exposed to such environmental stressors.

We know of only few human epigenetic studies that have assessed the effects of maltreatment on gene expression. McGowan et al. (2009) observed differences in epigenetic regulation of hippocampal glucocorticoid receptor expression (including increased cytosine methylation of an $\mathrm{NR} 3 \mathrm{C} 1$ promoter) in suicide victims with a history of childhood abuse, as compared with either suicide victims with no childhood abuse or controls. Interestingly, the epigenetic effects observed in the childhood abuse victims of this human study were comparable to the effects observed for the rats with low licking and grooming and reduced arched back nursing mothers (Weaver et al., 2004). Another recent study suggested that long-lasting changes in methylation of the 5-HTT promoter region could explain some of the association between childhood sexual abuse and symptoms of antisocial personality disorder in women (Beach et al., 2011). To our knowledge, no studies have looked at how baseline genotype differences may limit the extent and nature of epigenetic changes following maltreatment to provide a more mechanistic understanding of maltreatment GxE interactions. Finally, it should be noted that epigenetic processes, such as DNA methylation, regulate tissue specific gene expression. One consequence for human research is that this limits our ability to directly characterize epigenetic modification of neural structures or central tissues implicated in stress regulation. This is in contrast to rodent models where it is possible to assay tissue from cortical structures (e.g., Roth et al., 2009). While researchers have attempted to circumvent this limitation by using post-mortem tissue, this severely constrains the potential of further research in 
humans. It should be possible, however, to establish the association between patterns of epigenetic modification of accessible tissues, such as T cells in the blood or cells from buccal cheek swabs and specific developmental experiences, such as maltreatment. There is increasing evidence that measuring epigenetic changes longitudinally using such cells can provide meaningful information with regard to pathophysiology (e.g., Mill, 2011).

\section{SUMMARY: GENETICS OF RESILIENCE AND VULNERABILITY}

There are genetic influences on individual differences in the psychiatric outcomes associated with maltreatment. Recent GxE interaction studies suggest that certain polymorphisms may confer vulnerability or resilience to maltreatment, for example in terms of later levels of PTSD, depression, or antisocial behavior. Epigenetics is providing an exciting new avenue of research that aims to understand the mechanisms by which gene expression is influenced by exposure to environmental stressors and protective factors.

\section{LIMITATIONS OF CURRENT RESEARCH}

It is important to highlight several limitations that characterize many of the research studies investigating maltreatment. Firstly, all, but one (Carrion et al., 2007) of the brain imaging studies included in this review are cross-sectional, therefore no conclusions can be made on the causal effect of maltreatment on the brain; indeed it is possible (albeit unlikely) that the reported brain differences might represent a risk factor for exposure to maltreatment that in turn increases the risk of developing psychopathology. Secondly, the studies on adult samples have all relied on subjective retrospective reporting of maltreatment, which is liable to errors in recall that may reduce the reliability and validity of the data collected. Thirdly, researchers in the field have struggled to recruit and assess samples of children and adults that are readily comparable. Samples labeled "maltreated" have often been highly heterogeneous, drawn from different contexts (e.g., residential settings vs. home environments) and have been characterized by very different maltreatment histories. There is an increasing recognition of the need to improve the construct validity of measures that assess maltreatment type (Herrenkohl and Herrenkohl, 2009) as well as improve our accuracy in gaging maltreatment severity (Litrownik et al., 2005). If findings across studies are to be meaningfully compared, future studies need to meet the challenge of becoming more systematic in delineating maltreatment type, chronicity, frequency, and even perpetrator identity in their samples. There are some notable exceptions where researchers are already working to address these challenges (e.g., Andersen et al., 2008; Cicchetti and Rogosch, 2001). Fourthly, as noted earlier, many studies of adults and children have tended to recruit individuals with PTSD, particularly studies assessing structural brain differences. This approach makes it difficult to tease apart effects unique to maltreatment experience and current psychopathology. However, there now are a number of new studies that have recruited children who have experienced maltreatment but who do not present with PTSD (e.g., Hanson et al., 2010). Finally, it is worth noting the relatively small sample sizes that have characterized some of the studies reviewed here, particularly in several neuroimaging studies. There are undoubtedly real practical barriers that make recruiting such samples of children difficult, but larger samples would certainly improve statistical power, and allow us to better understand individual differences. These limitations should act to caution any strong conclusions regarding the neurobiological developmental trajectories of children experiencing maltreatment.

\section{CLINICAL IMPLICATIONS}

There is good evidence that early adversity in the form of childhood maltreatment is associated with poor outcome across a range of domains; in our view the evidence reviewed here suggests that this association is likely to be reflected, at least in part, at the neurobiological level. Specifically it appears that an early hostile environment contributes to stress-induced changes in the child's neurobiological systems that may be adaptive in the short-term but which reap long-term costs. These costs can be conceptualized at both the biological and psychological level. At the biological level we know from animal and human studies that chronic exposure to early stress is associated with atypical levels of stress hormones that may have an effect on the structure and function of the neurobiological systems that underpin social and psychological functioning (e.g., Arborelius et al., 1999; McEwen and Gianaros, 2010). At the psychological level it is possible that attentional and emotional systems adapt, such that they may become more effective in detecting and processing social threat but less able to successfully negotiate other aspects of social interaction (Pollak, 2008). One might speculate that these psychological changes ultimately become manifest as clinical symptoms in some children, for example as attentional difficulties or in the form of reactive aggression.

While neurobiological and genetic research has genuine longterm potential to inform clinical practice (Cicchetti and Gunnar, 2008; McCrory et al., 2010), it has already contributed to a broadening of our developmental narrative when thinking about how disruption to early caregiving can impact on a child's psychological and emotional development. Research at the neuroendocrine level - that has documented changes in the functioning of the HPA axis in children and adults who have experienced maltreatment - is probably the most advanced in this regard. Maternal behavior, for example, has been shown to be predictive of how well very young infants respond to everyday stressors: infants with mothers demonstrating higher quality maternal behavior, including greater sensitivity, show lower cortisol responses (Albers et al., 2008). Similarly, attachment security has been found to be associated with a child's pattern of stress reactivity to novel and stressful environments, such as entering child care for the first time (Ahnert et al., 2004). In securely attached infants the presence of their mother serves a stress protective function, indicated by lower levels of cortisol production when adapting to a novel environment; this contrasts with higher levels of cortisol production in insecurely attached infants (Ahnert et al., 2004). Such variation in normative samples illustrates how sensitively the neurobiological system is calibrated by the behavior of the caregiver who is tasked both with creating a safe micro-environment for the child and with helping the child regulate their own emotional states. In other words, patterns of sensitive, responsive, and attentive caregiving provides an external mechanism that can help regulate glucocorticoid and other stress responses (Nachmias et al., 1996; Gunnar and Donzella, 2002). This review has highlighted the consequences of maltreatment where such scaffolding is markedly 
absent and a child is forced to regulate their own levels of stress and/or manage heightened levels of negative affect in the environment. Sadly, in some cases it is the caregiver themselves who may be the source of stress for the child. As we have seen, this may lead to developmental adaptation of the HPA axis with psychological and biological consequences that increase long-term vulnerability for psychopathology (Gunnar and Cheatham, 2003).

A greater understanding of how the quality of caregiving can alter a child's stress reactivity has prompted several studies where the effectiveness of an intervention has been partly evaluated by assessing a child's cortisol reactivity under mild stress. Dozier et al. (2006a,b), for example, have investigated patterns of cortisol reactivity in children following an attachment-based intervention for foster parents. Children whose foster parents received this intervention essentially showed a normalization of cortisol responses to a social stressor (Dozier et al., 2008), demonstrating that clinical interventions may have the capacity to help recalibrate a child's stress reactivity.

While these studies investigating the relationship between indices of a child's HPA axis functioning and parenting have clear clinical relevance, the field of brain imaging lags somewhat behind in this regard. As yet, there is limited scope for explicit implications to be drawn from existing brain imaging research. Arguably there are several reasons what this is the case. Firstly, structural brain imaging studies have generally not aimed to explore the functional significance of observed brain differences in maltreated and non-maltreated children. Rather the interpretation of an observed difference is generally made in the context of our existing neurocognitive framework regarding the function of a given region. For many brain regions such a framework remains sparsely delineated, particularly within child samples. There have been a number of notable exceptions to this rule. In a recent study, Hanson et al. (2010) investigated not only structural differences in a region implicated in social functioning (the OFC) but investigated whether such differences were associated with impairments in actual social functioning of the children who participated in the study. Establishing brain-behavior correlations in this way is an important advance in building a more clinically relevant framework within which structural brain imaging findings can be meaningfully interpreted. Ultimately these correlational studies need to be complemented by longitudinal as well as by intervention studies that will allow changes in the child's environment and behavior to be measured alongside changes in brain structure and function. Such an approach is necessary if we are to begin to make even tentative inferences regarding causality.

Secondly our ability to draw clinical implications is constrained by our limited understanding of how neurobiological sensitivity to stress varies across development. This issue is not straightforward for the simple fact that brain areas are characterized by regional variation in rates of maturation; in other words, different brain regions develop at different rates (Gogtay et al., 2004). Therefore a given brain region may be more or less susceptible to the impact of maltreatment at a given stage in development. The consequence of this for researchers is that the same experience may lead to different patterns of brain abnormality depending on when a child is exposed to a given traumatogenic event. Andersen et al. (2008), who employed an innovative cross-sectional design, have reported preliminary evidence for this phenomenon. They aimed to investigate whether the experience of sexual abuse at different ages had specific effects in terms of regional brain volume. Twentysix young women aged between 18 and 24 who had experienced repeated episodes of childhood sexual abuse were compared with non-abused controls. The authors reported that hippocampal volume was reduced in association with childhood sexual abuse at ages 3-5 years and ages 11-13 years; CC volume was reduced with childhood sexual abuse at ages 9-10 years, and frontal cortex volume was reduced in subjects with childhood sexual abuse at ages 14-16 years. The authors concluded that different brain regions are likely to have unique windows of vulnerability to the effects of traumatic stress. This study highlights the possibility that the same maltreatment experience (in this case, sexual abuse) may have very different effects on brain structure depending on the age at which the abuse was experienced. It might be conjectured that these windows of vulnerability would be differentially susceptible to different forms of traumatic stress or maltreatment; however, further research is required to support such a hypothesis.

For most clinicians, a third limitation of the existing brain imaging literature pertains to the populations of children investigated. As noted earlier, many of the structural studies have focused on children presenting with clinically diagnosed PTSD, making it difficult to identify the specific correlates that are uniquely associated with maltreatment as opposed to those that might reflect predisposition to PTSD. To date the two fMRI studies of emotional processing have recruited children who have experienced early institutionalization and subsequent adoption. These children, who have experienced a diverse range of early stressors - most of which are undocumented - are very unlikely to be representative of the community samples typically referred to social services. Community based familial maltreatment, including physical, sexual, and emotional abuse as well as neglect and domestic violence characterize the majority who present to mental health clinics. These are not rare experiences, with 896,000 cases of substantiated maltreatment in the USA alone during 2005 (U.S. Department of Health and Human Services, Administration on Children, Youth, and Families, 2007). Despite this, we know almost nothing about the functional neural correlates of such experiences in these children, which limits our ability to make clinically informed inferences.

Recent years have increased our understanding of geneenvironment interactions that may increase the likelihood of psychopathology in children exposed to maltreatment. From a clinical perspective this helps provide a rationale as to the potential for individual variability in outcome for children exposed to similar traumatic experiences. In the field of $\mathrm{GxE}$ research it is recognized that advances will be contingent on improvements in how environmental influences are quantified, and precision in identifying the timing of their occurrence (Lenroot and Giedd, 2011). However, there is preliminary evidence that genetic polymorphisms may also help account for the potential variability in clinical outcome. In a study of 1 - to 3-year-old children with externalizing problems Bakermans-Kranenburg et al. (2008) found a moderating role for the dopamine D4 receptor (DRD4) in a video-feedback intervention study designed to improve maternal sensitivity and discipline. The intervention was effective primarily in those children with the DRD4 7-repeat polymorphism. This is 
the first study to provide preliminary evidence that gene by environment interactions may play an important role in explaining the differential effectiveness of a given intervention. We remain a long way, however, from being able to tailor interventions to specific groups of children on the basis of genetic information. Nonetheless, improving our conceptual understanding of the factors underpinning outcome variability will represent an important advance in our efforts to treat more effectively the wide range of problems that are known to be associated with maltreatment.

\section{CONCLUSION}

While there is now accumulating evidence indicating an association between neurobiological change and childhood maltreatment there remains a need for caution in how such evidence is interpreted. Much of the research to date has been based on very mixed samples of children or adults with diverse experiences of early adversity. This partly derives from the complexities inherent in the defining and assessing maltreatment type, given that abusive experiences seldom occur in isolation. Nonetheless greater precision and homogeneity in how groups are characterized in relation to maltreatment experience, age range, socio-economic status, and intellectual ability are required, as too is the need for

\section{REFERENCES}

Ahnert, L., Gunnar, M. R., Lamb, M. E., and Barthel, M. (2004). Transition to child care: associations with infantmother attachment, infant negative emotion, and cortisol elevations. Child Dev. 75, 639-650.

Albers, E. M., Marianne RiksenWalraven, J., Sweep, F. C. G. J., and Weerth, C. D. (2008). Maternal behavior predicts infant cortisol recovery from a mild everyday stressor. J. Child. Psychol. Psychiatry 49, 97-103.

Amodio, D. M., and Frith, C. D. (2006). Meeting of minds: the medial frontal cortex and social cognition. Nat. Rev. Neurosci. 7, 268-277.

Andersen, S. L., Tomada, A., Vincow, E. S., Valente, E., Polcari, A., and Teicher, M. H. (2008). Preliminary evidence for sensitive periods in the effect of childhood sexual abuse on regional brain development. J. Neuropsychiatry Clin. Neurosci. 20, 292301.

Arborelius, L., Owens, M. J., Plotsky, P. M., and Nemeroff, C. B. (1999). The role of corticotropin-releasing factor in depression and anxiety disorders. J. Endocrinol. 160, 1-12.

Bakermans-Kranenburg, M. J., Van Ijzendoorn, M. H., Pijlman, F. T. A., Mesman, J., and Juffer, F. (2008). Experimental evidence for differential susceptibility: dopamine D4 receptor polymorphism (DRD4 VNTR) moderates intervention effects on toddlers' externalizing behavior in a randomized controlled trial. Dev. Psychol. 44, 293-300.

Beach, S. R., Brody, G. H., Todorov, A. A., Gunter, T. D., and Philibert, R. A. (2011). Methylation at 5HTT mediates the impact of child sex abuse on women's antisocial behavior: an examination of the Iowa adoptee sample. Psychosom. Med. 73, 83-87.

Bremner, J. D., Randall, P., Vermetten, E., Staib, L., Bronen, R. A., Mazure, C., Capelli, S., Mccarthy, G., Innis, R. B., and Charney, D. S. (1997). Magnetic resonance imaging-based measurement of hippocampal volume in posttraumatic stress disorder related to childhood physical and sexual abuse - a preliminary report. Biol. Psychiatry 41, 23-32.

Carrion, V. G., Garrett, A., Menon, V., Weems, C. F., and Reiss, A. L. (2008). Posttraumatic stress symptoms and brain function during a responseinhibition task: an fMRI study in youth. Depress. Anxiety 25, 514-526.

Carrion, V. G., Haas, B. W., Garrett, A., Song, S., and Reiss, A. L. (2010). Reduced hippocampal activity in youth with posttraumatic stress symptoms: an fMRI study. $J$. Pediatr. Psychol. 35, 559-569.

Carrion, V. G., Weems, C. F., Eliez, S., Patwardhan, A., Brown, W., Ray, R. D., and Reiss, A. L. (2001). Attenuation of frontal asymmetry in pediatric posttraumatic stress disorder. Biol. Psychiatry 50, 943-951.

Carrion, V. G., Weems, C. F., Ray, R. D., Glaser, B., Hessl, D., and

longitudinal and intervention studies. This will assist in making more meaningful inferences about the significance of any observed neurobiological differences.

Nonetheless, the studies reviewed here support a growing consensus that maltreatment contributes to stress-induced changes in a child's neurobiological systems. While these changes may be adaptive in the short-term it is hypothesized that they contribute to heightened risk for psychopathology over the longer term. There is a need to specify with more precision the psychological factors that may mediate the association with poor behavioral outcome, both in terms of adaptations to psychological processes (e.g., attentional hypervigilance to threat) and in terms of internal representations of self and others (e.g., schemas or internal working models). The longer-term goal is to establish a clearer picture of the links between environmental stress, neurobiologi$\mathrm{cal}$, and neuroendocrine change and the ways in which these may potentiate and shape social, affective, and cognitive development.

\section{ACKNOWLEDGMENTS}

Eamon McCrory and Stephane A. De Brito are supported by RES-061-25-0189 from the ESRC, and Eamon McCrory and Essi Viding are also supported by RES-062-23-2202 from ESRC and BARDA-53229 from the British Academy.

Reiss, A. L. (2002). Diurnal salivary cortisol in pediatric posttraumatic stress disorder. Biol. Psychiatry 51, 575-582.

Carrion, V. G., Weems, C. F., and Reiss, A. L. (2007). Stress predicts brain changes in children: a pilot longitudinal study on youth stress, posttraumatic stress disorder, and the hippocampus. Pediatrics 119, 509-516.

Carrion, V. G., Weems, C. F., Watson, C., Eliez, S., Menon, V., and Reiss, A. L. (2009). Converging evidence for abnormalities of the prefrontal cortex and evaluation of midsagittal structures in pediatric posttraumatic stress disorder: an MRI study. Psychiatry Res. 172, 226-234.

Caspi, A., Mcclay, J., Moffitt, T., Mill, J., Martin, J., Craig, I. W., Taylor, A., and Poulton, R. (2002). Role of genotype in the cycle of violence in maltreated children. Science 297, 851-854.

Caspi, A., and Moffitt, T. E. (2006). Gene-environment interactions in psychiatry: joining forces with neuroscience. Nat. Rev. Neurosci. 7, 583-590.

Choi, J., Jeong, B., Rohan, M. L., Polcari, A. M., and Teicher, M. H. (2009). Preliminary evidence for white matter tract abnormalities in young adults exposed to parental verbal abuse. Biol. Psychiatry 65, 227-234.

Cicchetti, D., and Curtis, W. J. (2005). An event-related potential study of the processing of affective facial expressions in young children who experienced maltreatment during the first year of life. Dev. Psychopathol. 17, 641-677.

Cicchetti, D., and Gunnar, M. R. (2008). Integrating biological measures into the design and evaluation of preventive interventions. Dev. Psychopathol. 20, 737-743.

Cicchetti, D., and Rogosch, F. A. (2001). The impact of child maltreatment and psychopathology on neuroendocrine functioning. Dev. Psychopathol. 13, 783-804.

Cicchetti, D., Rogosch, F. A., and Cox Kearns, S. (2001). Diverse patterns of neuroendocrine activity in maltreated children. Dev. Psychopathol. 13, 677-693.

Cicchetti, D., Rogosch, F. A., and SturgeApple, M. L. (2007). Interactions of child maltreatment and serotonin transporter and monoamine oxidase A polymorphisms: depressive symptomatology among adolescents from low socioeconomic status backgrounds. Dev. Psychopathol. 19, 1161-1180.

Craig, I. W. (2007). The importance of stress and genetic variation in human aggression. Bioessays 29, 227-236.

Croy, I., Schellong, J., Gerber, J., Joraschky, P., Iannilli, E., and Hummel, T. (2010). Women with a history of childhood maltreatment exhibit more activation in association areas following non-traumatic olfactory stimuli: a fMRI study. PLoS ONE 5, e9362. doi: 10.1371/journal.pone.0009362 
Currie, J., and Widom, C. S. (2010). Long-term consequences of child abuse and neglect on adult economic well-being. Child Maltreat. 15, 111-120.

Davidson, R. J., Putnam, K. M., and Larson, C. L. (2000). Dysfunction in the neural circuitry of emotion regulation - a possible prelude to violence. Science 289, 591-594.

De Bellis, M. D., Baum, A. S., Birmaher, B., Keshavan, M. S., Eccard, C. H., Boring, A. M., Jenkins, F. J., and Ryan, N. D. (1999a). Developmental traumatology part I: biological stress systems. Biol. Psychiatry 45, 1259-1270.

De Bellis, M. D., Keshavan, M. S., Clark, D. B., Casey, B. J., Giedd, J. N., Boring, A. M., Frustaci, K., and Ryan, N. D. (1999b). Developmental traumatology part II: brain development. Biol. Psychiatry 45, 1271-1284.

De Bellis, M. D., Chrousos, G. P., Dorn, L. D., Burke, L., Helmers, K., Kling, M. A., Trickett, P. K., and Putnam, F. W. (1994). Hypothalamic-pituitaryadrenal axis dysregulation in sexually abused girls. J. Clin. Endocrinol. Metab. 78, 249-255.

De Bellis, M. D., and Keshavan, M. S. (2003). Sex differences in brain maturation in maltreatment-related pediatric posttraumatic stress disorder. Neurosci. Biobehav. Rev. 27, 103-117.

De Bellis, M. D., Keshavan, M. S., Shifflett, H., Iyengar, S., Beers, S. R., Hall, J., and Moritz, G. (2002). Brain structures in pediatric maltreatment-related posttraumatic stress disorder: a sociodemographically matched study. Biol. Psychiatry 52, 1066-1078.

Dillon, D. G., Holmes, A. J., Birk, J. L., Brooks, N., Lyons-Ruth, K., and Pizzagalli, D. A. (2009). Childhood adversity is associated with left basal ganglia dysfunction during reward anticipation in adulthood. Biol. Psychiatry 66, 206-213.

Dozier, M., Manni, M., Gordon, M. K., Peloso, E., Gunnar, M. R., StovallMcclough, K. C., Eldreth, D., and Levine, S. (2006a). Foster children's diurnal production of cortisol: an exploratory study. Child Maltreat. 11, 189-197.

Dozier, M., Peloso, E., Lindhiem, O., Gordon, M. K., Manni, M., Sepulveda, S., Ackerman, J., Bernier, A., and Levine, S. (2006b). Developing evidence-based interventions for foster children: an example of a randomized clinical trial with infants and toddlers. J. Soc. Issues 62, 767-785.

Dozier, M., Peloso, E., Lewis, E., Laurenceau, J. P., and Levine, S.
(2008). Effects of an attachmentbased intervention on the cortisol production of infants and toddlers in foster care. Dev. Psychopathol. 20, 845-869.

Eluvathingal, T. J., Chugani, H. T., Behen, M. E., Juhãsz, C., Muzik, O., Maqbool, M., Chugani, D. C., and Makki, M. (2006). Abnormal brain connectivity in children after early severe socioemotional deprivation: a diffusion tensor imaging study. Pediatrics 117, 2093-2100.

Feder, A., Nestler, E. J., and Charney, D. S. (2009). Psychobiology and molecular genetics of resilience. Nat. Rev. Neurosci. 10, 446-457.

Fries, E., Hesse, J., Hellhammer, J., and Hellhammer, D. H. (2005). A new view on hypocortisolism. Psychoneuroendocrinology 30, 1010-1016.

Fuster, J. M. (1997). The Prefrontal Cortex: Anatomy, Physiology, and Neurophysiology of the Frontal Lobe. Philadelphia: Lippincott-Raven.

Giedd, J. N., Rumsey, J. M., Castellanos, F. X., Rajapakse, J. C., Kaysen, D., Vaituzis, A. C., Vauss, Y. C., Hamburger, S. D., and Rapoport, J. L. (1996). A quantitative MRI study of the corpus callosum in children and adolescents. Brain Res. Dev. Brain Res. 91, 274-280.

Gilbert, R., Kemp, A., Thoburn, J., Sidebotham, P., Radford, L., Glaser, D., and Macmillan, H. L. (2009). Recognising and responding to child maltreatment. Lancet 373, 167-180.

Gilbertson, M. W., Shenton, M. E., Ciszewski, A., Kasai, K., Lasko, N. B., Orr, S. P., and Pitman, R. K. (2002). Smaller hippocampal volume predicts pathologic vulnerability to psychological trauma. Nat. Neurosci. 5 , 1242-1247.

Gogtay, N., Giedd, J. N., Lusk, L., Hayashi, K. M., Greenstein, D., Vaituzis, A. C., Nugent III, T. F., Herman, D. H., Clasen, L. S., Toga, A. W., Rapoport, J. L., and Thompson, P. M. (2004). Dynamic mapping of human cortical development during childhood through early adulthood. Proc. Natl. Acad. Sci. U.S.A 101, 8174-8179.

Goodyer, I. M., Herbert, J., and Altham, P. M. E. (1998). Adrenal steroid secretion and major depression in 8- to 16-year-olds, III. Influence of cortisol/DHEA ratio at presentation on subsequent rates of disappointing life events and persistent major depression. Psychol. Med. 28, 265-273.

Govindan, R. M., Behen, M. E., Helder, E., Makki, M. I., and Chugani, H. T. (2010). Altered water diffusivity in cortical association tracts in children with early deprivation identified with tract-based spatial statistics (TBSS). Cereb. Cortex 20 561-569.

Grant, M. M., Cannistraci, C., Hollon, S. D., Gore, J., and Shelton, R. (2011). Childhood trauma history differentiates amygdala response to sad faces within MDD. J. Psychiatr. Res. 45, 886-895.

Gunnar, M. R., and Cheatham, C. L. (2003). Brain and behavior interface: stress and the developing brain. Infant Ment. Health J. 24, 195-211.

Gunnar, M. R., and Donzella, B. (2002). Social regulation of the cortisol levels in early human development. Psychoneuroendocrinology 27 199-220.

Gunnar, M. R., Fisher, P. A., Dozier, M., Fox, N., Levine, S., Neal, C., Pollak, S., Plotsky, P., Sanchez, M., and Vazquez, D. (2006). Bringing basic research on early experience and stress neurobiology to bear on preventive interventions for neglected and maltreated children. Dev. Psychopathol. 18, 651-677.

Hanson, J. L., Chung, M. K., Avants, B. B., Shirtcliff, E. A., Gee, J. C., Davidson, R. J., and Pollak, S. D. (2010). Early stress is associated with alterations in the orbitofrontal cortex: a tensor-based morphometry investigation of brain structure and behavioral risk. J. Neurosci 30 , 7466-7472.

Hart, J., Gunnar, M., and Cicchetti, D. (1995). Salivary cortisol in maltreated children: evidence of relations between neuroendocrine activity and social competence. Dev. Psychopathol. 7, 11-26.

Hart, J., Gunnar, M., and Cicchetti, D. (1996). Altered neuroendocrine activity in maltreated children related to symptoms of depression. Dev. Psychopathol. 8, 201-214.

Heim, C., Mletzko, T., Purselle, D., Musselman, D. L., and Nemeroff, C. B. (2008). The dexamethasone/corticotropinreleasing factor test in men with major depression: role of childhood trauma. Biol. Psychiatry 63, 398-405.

Heim, C., Newport, D. J., Wagner, D., Wilcox, M. M., Miller, A. H. and Nemeroff, C. B. (2002). The role of early adverse experience and adulthood stress in the prediction of neuroendocrine stress reactivity in women: a multiple regression analysis. Depress. Anxiety 15, $117-125$.

Herrenkohl, R. C., and Herrenkohl, T. I. (2009). Assessing a child's experience of multiple maltreatment types: some unfinished business. J. Fam. Violence 24, 485-496.
Izard, C. E., and Harris, P. (1995). "Emotional development and developmental psychopathology," in Developmental Psychopathology: Vol. I: Theories and Methods, eds D. Cicchetti and J. Cohen (New York: John Wiley), 467-503.

Jackowski, A. P., De Araújo, C. M., De Lacerda, A. L. T., De Jesus Mari, J., and Kaufman, J. (2009). Neurostructural imaging findings in children with post-traumatic stress disorder: brief review. Psychiatry Clin. Neurosci. 63, 1-8.

Jackowski, A. P., Douglas-Palumberi, H., Jackowski, M., Win, L., Schultz, R. T., Staib, L. W., Krystal, J. H., and Kaufman, J. (2008). Corpus callosum in maltreated children with posttraumatic stress disorder: a diffusion tensor imaging study. Psychiatry Res. 162, 256-261.

Kaufman, J. (1991). Depressive disorders in maltreated children. J. Am Acad. Child Adolesc. Psychiatry 30, 257-265.

Kaufman, J., Birmaher, B., Perel, J., Dahl, R. E., Moreci, P., Nelson, B., Wells, W., and Ryan, N. D. (1997). The corticotropin-releasing hormone challenge in depressed abused, depressed nonabused, and normal control children. Biol. Psychiatry 42, 669-679.

Kaufman, J., Yang, B. Z., DouglasPalumberi, H., Grasso, D., Lipschitz, D., Houshyar, S., Krystal, J. H., and Gelernter, J. (2006). Brain-derived neurotrophic factor5-HTTLPR gene interactions and environmental modifiers of depression in children. Biol. Psychiatry 59, 673-680.

Kitayama, N., Brummer, M., Hertz, L., Quinn, S., Kim, Y., and Bremner, J. D. (2007). Morphologic alterations in the corpus callosum in abuse-related posttraumatic stress disorder: a preliminary study. J. Nerv. Ment. Dis. 195, 1027-1029.

Kitterle, F. (1995). Hemispheric Communication: Mechanisms and Models. Hillsdale, NJ: Laurence Erlbaum Associates, Inc.

Koenen, K. C., Nugent, N. R., and Amstadter, A. B. (2008). Geneenvironment interaction in posttraumatic stress disorder: review, strategy and new directions for future research. Eur. Arch. Psychiatry Clin. Neurosci. 258, 82-96.

Lansford, J. E., Dodge, K. A., Pettit, G. S., Bates, J. E., Crozier, J., and Kaplow, J. (2002). A 12-year prospective study of the long-term effects of early child physical maltreatment on psychological, behavioral, and academic problems in adolescence. Arch. Pediatr. Adolesc. Med. 156, 824-830. 
Lenroot, R. K., and Giedd, J. N. (2011). Annual research review: developmental considerations of gene by environment interactions. J. Child Psychol. Psychiatry 52,429-441.

Litrownik, A. J., Lau, A., English, D. J., Briggs, E., Newton, R. R., Romney, S., and Dubowitz, H. (2005). Measuring the severity of child maltreatment. Child Abuse Negl. 29, 553-573.

Liu, D., Diorio, J., Tannenbaum, B., Caldji, C., Francis, D., Freedman, A., Sharma, S., Pearson, D., Plotsky, P. M., and Meaney, M. J. (1997). Maternal care, hippocampal glucocorticoid receptors, and hypothalamicpituitary-adrenal responses to stress. Science 277, 1659-1662.

Lotfipour, S., Ferguson, E., Leonard, G., Perron, M., Pike, B., Richer, L., Seguin, J. R., Toro, R., Veillette, S., Pausova, Z., and Paus, T. (2009). Orbitofrontal cortex and drug use during adolescence: role of prenatal exposure to maternal smoking and BDNF genotype. Arch. Gen. Psychiatry 66, 1244-1252.

Lupien, S. J., De Leon, M., De Santi, S., Convit, A., Tarshish, C., Nair, N. P. V., Thakur, M., Mcewen, B. S., Hauger, R. L., and Meaney, M. J. (1998). Cortisol levels during human aging predict hippocampal atrophy and memory deficits. Nat. Neurosci. 1, 69-73.

Lupien, S. J., Mcewen, B. S., Gunnar, M. R., and Heim, C. (2009). Effects of stress throughout the lifespan on the brain, behaviour and cognition. Nat. Rev. Neurosci. 10, 434-445.

Maheu, F. S., Dozier, M., Guyer, A. E., Mandell, D., Peloso, E., Poeth, K., Jenness, J., Lau, J. Y., Ackerman, J. P., Pine, D. S., and Ernst, M. (2010). A preliminary study of medial temporal lobe function in youths with a history of caregiver deprivation and emotional neglect. Cogn. Affect. Behav. Neurosci. 10, 34-49.

McCrory, E., De Brito, S. A., and Viding, E. (2010). Research review: the neurobiology and genetics of maltreatment and adversity. J. Child. Psychol. Psychiatry 51, 1079-1095.

McEwen, B. S. (1999). Stress and hippocampal plasticity. Annu. Rev. Neurosci. 22, 105-122.

McEwen, B. S., and Gianaros, P. J. (2010). Central role of the brain in stress and adaptation: links to socioeconomic status, health, and disease. Ann. N. Y. Acad. Sci. 1186, 190-222.

McGowan, P. O., Sasaki, A., D’alessio, A. C., Dymov, S., Labonté, B., Szyf, M., Turecki, G., and Meaney, M. J. (2009). Epigenetic regulation of the glucocorticoid receptor in human brain associates with childhood abuse. Nat. Neurosci. 12, 342-348.

Meewisse, M. L., Reitsma, J. B., De Vries, G. J., Gersons, B. P. R., and Olff, M. (2007). Cortisol and posttraumatic stress disorder in adults: systematic review and meta-analysis. Br. J. Psychiatry 191, 387-392.

Mehta, M. A., Golembo, N. I., Nosarti, C., Colvert, E., Mota, A., Williams, S. C. R., Rutter, M., and Sonuga-Barke, E. J. S. (2009). Amygdala, hippocampal and corpus callosum size following severe early institutional deprivation: the English and Romanian Adoptees Study Pilot. J. Child. Psychol. Psychiatry 50, 943-951.

Meyer-Lindenberg, A., Buckholtz, J. W., Kolachana, B., Hariri, A. R., Pezawas, L., Blasi, G., Wabnitz, A., Honea, R., Verchinski, B., Callicott, J. H., Egan, M., Mattay, V., and Weinberger, D. R. (2006). Neural mechanisms of genetic risk for impulsivity and violence in humans. Proc. Natl. Acad. Sci. U.S.A. 103, 6269-6274.

Mill, J. (2011). Toward an integrated genetic and epigenetic approach to Alzheimer's disease. Neurobiol. Aging 32, 1188-1191.

Miller, E. K., and Cohen, J. D. (2001). An integrative theory of prefrontal cortex function. Annu. Rev. Neurosci. 24, 167-202.

Miller, G. E., Chen, E., and Zhou, E. S. (2007). If it goes up, must it come down? Chronic stress and the hypothalamic-pituitaryadrenocortical axis in humans. Psychol. Bull. 133, 25-45.

Mizomuri, S. J. Y., Smith, D. M., and Puryear, C. B. (2007). "Mnemonic contributions of hippocampal place cells," in Neurobiology of Learning and Memory, eds J. Martinez and R. Kesner (Burlington, MA: Elsevier), 155-190.

Moffitt, T. E., Caspi, A., and Rutter, M. (2005). Strategy for investigating interactions between measured genes and measured environments. Arch. Gen. Psychiatry 62, 473-481.

Mueller, S. C., Maheu, F. S., Dozier, M., Peloso, E., Mandell, D., Leibenluft, E., Pine, D. S., and Ernst, M. (2010). Early-life stress is associated with impairment in cognitive control in adolescence: an fMRI study. Neuropsychologia 48, 3037-3044.

Nachmias, M., Gunnar, M., Mangelsdorf, S., Parritz, R. H., and Buss, K. (1996). Behavioral inhibition and stress reactivity: the moderating role of attachment security. Child Dev. 67, 508-522.

Neigh, G. N., Gillespie, C. F., and Nemeroff, C. B. (2009). The neurobiological toll of child abuse and neglect. Trauma Violence Abuse 10, 389-410.

Newport, D. J., Heim, C., Bonsall, R. Miller, A. H., and Nemeroff, C. B. (2004). Pituitary-adrenal responses to standard and low-dose dexamethasone suppression tests in adult survivors of child abuse. Biol. Psychiatry 55, 10-20.

Parker, S. W., and Nelson, C. A. (2005). The impact of early institutional rearing on the ability to discriminate facial expressions of emotion: an event-related potential study. Child Dev. 76, 54-72.

Parker, S. W., Nelson, C. A., Zeanah, C. H., Smyke, A. T., Koga, S. F., Fox, N. A., Marshall, P. J., and Woodward, H. R. (2005). An eventrelated potential study of the impact of institutional rearing on face recognition. Dev. Psychopathol. 17, 621-639.

Pears, K. C., Kim, H. K., and Fisher, P. A. (2008). Psychosocial and cognitive functioning of children with specific profiles of maltreatment. Child Abuse Negl. 32, 958-971.

Pederson, C. L., Maurer, S. H., Kaminski, P. L., Zander, K. A., Peters, C. M., Stokes-Crowe, L. A., and Osborn, R. E. (2004). Hippocampal volume and memory performance in a community-based sample of women with posttraumatic stress disorder secondary to child abuse. J. Trauma Stress 17, 37-40.

Phelps, E. A., and LeDoux, J. E. (2005). Contributions of the amygdala to emotion processing: from animal models to human behavior. Neuron 48, 175-187.

Plomin, R., Owen, M. J., and Mcguffin, P. (1994). The genetic basis of complex human behaviors. Science 264, 1733-1739.

Pollak, S. D. (2008). Mechanisms linking early experience and the emergence of emotions: illustrations from the study of maltreated children. Curr. Dir. Psychol. Sci. 17, 370-375.

Pollak, S. D., Cicchetti, D., Klorman, R., and Brumaghim, J. T. (1997). Cognitive brain event-related potentials and emotion processing in maltreated children. Child Dev. 68 773-787.

Pollak, S. D., Klorman, R., Thatcher, J. E., and Cicchetti, D. (2001). P3b reflects maltreated children's reactions to facial displays of emotion. Psychophysiology 38, 267-274.

Pollak, S. D., and Tolley-Schell, S. A. (2003). Selective attention to facial emotion in physically abused children. J. Abnorm. Psychol. 112, 323-338.
Rhee, S. H., and Waldman, I. D. (2002). Genetic and environmental influences on antisocial behavior: a meta-analysis of twin and adoption studies. Psychol. Bull. 128, 490-529.

Richert, K. A., Carrion, V. G., Karchemskiy, A., and Reiss, A. L. (2006). Regional differences of the prefrontal cortex in pediatric PTSD: an MRI study. Depress. Anxiety 23, 17-25.

Roth, T. L., Lubin, F. D., Funk, A. J., and Sweatt, J. D. (2009). Lasting epigenetic influence of early-life adversity on the BDNF gene. Biol. Psychiatry 65, 760-769.

Sapolsky, R. M., Uno, H., Rebert, C. S., and Finch, C. E. (1990). Hippocampal damage associated with prolonged glucocorticoid exposure in primates. J. Neurosci. 10, 2897-2902.

Shackman, J. E., Shackman, A. J., and Pollak, S. D. (2007). Physical abuse amplifies attention to threat and increases anxiety in children. Emotion 7, 838-852.

Shea, M. T., Yen, S., Pagano, M. E., Morey, L. C., Mcglashan, T. H., Grilo, C. M., Sanislow, C. A., Stout, R. L., Skodol, A. E., Gunderson, J. G. Bender, D. S., and Zanarini, M. C. (2004). Associations in the course of personality disorders and axis i disorders over time. J. Abnorm. Psychol. 113, 499-508.

Shirtcliff, E. A., Coe, C. L., and Pollak, S. D. (2009). Early childhood stress is associated with elevated antibody levels to herpes simplex virus type 1. Proc. Natl. Acad. Sci. U.S.A. 106, 2963-2967.

Sullivan, P. F., Neale, M. C., and Kendler, K. S. (2000). Genetic epidemiology of major depression: review and meta-analysis. Am. J. Psychiatry 157, 1552-1562.

Tarullo, A. R., and Gunnar, M. R. (2006). Child maltreatment and the developing HPA axis. Horm. Behav. 50, 632-639.

Taylor, A., and Kim-Cohen, J. (2007). Meta-analysis of gene-environment interactions in developmental psychopathology. Dev. Psychopathol. 19, 1029-1037.

Teicher, M. H., Andersen, S. L., Polcari, A., Anderson, C. M., Navalta, C. P., and Kim, D. M. (2003). The neurobiological consequences of early stress and childhood maltreatment. Neurosci. Biobehav. Rev. 27, 33-44.

Teicher, M. H., Dumont, N. L., Ito, Y., Vaituzis, C., Giedd, J. N., and Andersen, S. L. (2004). Childhood neglect is associated with reduced corpus callosum area. Biol. Psychiatry 56, 80-85. 
Tomoda, A., Suzuki, H., Rabi, K., Sheu, Y.-S., Polcari, A., and Teicher, M. H. (2009). Reduced prefrontal cortical gray matter volume in young adults exposed to harsh corporal punishment. Neuroimage 47, T66-T71.

Tottenham, N., Hare, T. A., Millner, A., Gilhooly, T., Zevin, J. D., and Casey, B. J. (2011). Elevated amygdala response to faces following early deprivation. Dev. Sci. 14, 190-204.

Tottenham, N., Hare, T. A., Quinn, B. T., Mccarry, T. W., Nurse, M., Gilhooly, T., Millner, A., Galvan, A., Davidson, M. C., Eigsti, I. M., Thomas, K. M., Freed, P. J., Booma, E. S., Gunnar, M. R., Altemus, M., Aronson, J., and Casey, B. J. (2010). Prolonged institutional rearing is associated with atypically large amygdala volume and difficulties in emotion regulation. Dev. Sci. 13, 46-61.

Tottenham, N., and Sheridan, M. A. (2010). A review of adversity, the amygdala and the hippocampus: a consideration of developmental timing. Front. Hum. Neurosci. 3:68. doi: 10.3389/neuro.09.068.2009

Treadway, M. T., Grant, M. M., Ding, Z., Hollon, S. D., Gore, J. C., and Shelton, R. C. (2009). Early adverse events, HPA activity and rostral anterior cingulate volume in
MDD. PLoS ONE 4, e4887. doi: 10.1371/journal.pone.0004887

Tsankova, N., Renthal, W., Kumar, A., and Nestler, E. J. (2007). Epigenetic regulation in psychiatric disorders. Nat. Rev. Neurosci. 8, 355-367.

U.S. Department of Health and Human Services, Administration on Children, Youth, and Families. (2007). Child Maltreatment 2005. Washington, DC: U.S. Government Printing Office.

van Goozen, S. H. M., and Fairchild, G. (2008). How can the study of biological processes help design new interventions for children with severe antisocial behavior? Dev. Psychopathol. 20, 941-973.

van Harmelen, A.-L., Van Tol, M.-J., Van Der Wee, N. J. A., Veltman, D. J., Aleman, A., Spinhoven, P., Van Buchem, M. A., Zitman, F. G., Pen$\operatorname{ninx}$, B. W. J. H., and Elzinga, B. M. (2010). Reduced medial prefrontal cortex volume in adults reporting childhood emotional maltreatment. Biol. Psychiatry 68, 832-838.

Vermetten, E., Schmahl, C., Lindner, S., Loewenstein, R. J., and Bremner, J. D. (2006). Hippocampal and amygdalar volumes in dissociative identity disorder. Am. J. Psychiatry 163, 630-636.

Viding, E., and Frith, U. (2006). Genes for susceptibility to violence lurk in the brain. Proc. Natl. Acad. Sci. U.S.A. 103, 6085-6086.

Viding, E., Williamson, D. E., and Hariri, A. R. (2006). Developmental imaging genetics: challenges and promises for translational research. Dev. Psychopathol. 18, 877-892.

Vyas, A., Bernal, S., and Chattarji, S. (2003). Effects of chronic stress on dendritic arborization in the central and extended amygdala. Brain Res. 965, 290-294.

Vythilingam, M., Heim, C., Newport, J. Miller, A. H., Anderson, E., Bronen, R., Brummer, M., Staib, L., Vermetten, E., Charney, D. S., Nemeroff, C. B., and Douglas Bremner, J. (2002). Childhood trauma associated with smaller hippocampal volume in women with major depression. Am. J. Psychiatry 159, 2072 2080.

Weaver, I. C. G., Cervoni, N., Champagne, F. A., D'alessio, A. C., Sharma, S., Seckl, J. R., Dymov, S., Szyf, M., and Meaney, M. J. (2004). Epigenetic programming by maternal behavior. Nat. Neurosci. 7, 847-854.

Weder, N., Yang, B. Z., DouglasPalumberi, H., Massey, J., Krystal, J. H., Gelernter, J., and Kaufman, J. (2009). MAOA genotype, maltreatment, and aggressive behavior: the changing impact of genotype at varying levels of trauma. Biol. Psychiatry 65, 417-424.

Woon, F. L., and Hedges, D. W. (2008). Hippocampal and amygdala volumes in children and adults with childhood maltreatment-related posttraumatic stress disorder: a meta-analysis. Hippocampus 18 , 729-736.

Conflict of Interest Statement: The authors declare that the research was conducted in the absence of any commercial or financial relationships that could be construed as a potential conflict of interest.

Received: 20 February 2011; accepted: 19 July 2011; published online: 28 July 2011. Citation: McCrory E, De Brito SA and Viding E (2011) The impact of childhood maltreatment: a review of neurobiological and genetic factors. Front. Psychiatry 2:48. doi: 10.3389/fpsyt.2011.00048

This article was submitted to Frontiers in Child and Neurodevelopmental Psychiatry, a specialty of Frontiers in Psychiatry. Copyright $(52011$ McCrory, De Brito and Viding. This is an open-access article subject to a non-exclusive license between the authors and Frontiers Media SA, which permits use, distribution and reproduction in other forums, provided the original authors and source are credited and other Frontiers conditions are complied with. 